\title{
Correction to: Does climate change framing matter? Evidence from an experiment of crop advisors in the Midwestern United States
}

\author{
Ajay S. Singh ${ }^{1} \cdot$ Sarah P. Church ${ }^{2} \cdot$ Layla Dang $^{3} \cdot$ Erin P. Hennes $^{3} \cdot$ Linda S. Prokopy $^{4}$ \\ Published online: 12 June 2020 \\ (C) Springer Nature B.V. 2020
}

\section{Correction to: Climatic Change \\ https://doi.org/10.1007/s10584-020-02703-8}

During proof correction, the author supplied new images that were unfortunately not included. The original article has been updated to include the correct images.

\section{Affiliations}

\author{
Ajay S. Singh ${ }^{1} \cdot$ Sarah P. Church ${ }^{2} \cdot$ Layla Dang $^{3} \cdot$ Erin P. Hennes $^{3} \cdot$ Linda S. Prokopy $^{4}$ \\ 1 Department of Environmental Studies, California State University, 6001 J Street, Sacramento, CA 95818, USA \\ 2 Department of Earth Sciences, Montana State University, Traphagen Hall, Bozeman, MT 59717, USA \\ 3 Department of Psychological Sciences, Purdue University, 703 Third Street, West Lafayette, IN 47907, USA \\ 4 Department of Forestry and Natural Resources, Purdue University, 195 Marsteller Street, West Lafayette, IN \\ 47907, USA
}

The online version of the original article can be found at https://doi.org/10.1007/s10584-020-02703-8

\author{
Ajay S. Singh \\ Singh@csus.edu \\ Sarah P. Church \\ Sarah.church@montana.edu \\ Layla Dang \\ dang24@purdue.edu \\ Erin P. Hennes \\ Ehennes@purdue.edu \\ Linda S. Prokopy \\ Lprokopy@purdue.edu
}

Extended author information available on the last page of the article 